\title{
The Triple Helix Model of Innovation
}

\author{
Safiullin L.N. \\ Fatkhiev A.M. \\ Grigorian K.A. \\ Kazan (Volga region) Federal University, 18, Kremlyovskaya Street, Kazan, \\ Repablic of Tatarstan, Russian Federation, 420008
}

\section{Doi:10.5901/mjss.2014.v5n18p203}

\begin{abstract}
Nowadays in a knowledge-based society, university, industry and government play important roles and form a triple helix in innovation stimulating. Such interaction is the source of the creation and development of incubator movements, research centres and venture capital, which can be private, public or social. The implementation of this model is the basis of favorable innovation climate, as it promotes the development of its components, their combination promotes a synergistic effect, increases innovation activity.
\end{abstract}

Keywords: Triple Helix, innovation networks, globalization, university, government, industry, innovation risks.

\section{Introduction}

Inadaptability and instability of post-industrial society institutions to the process of intellectualization and informatization of economic space, high turbulence of the external environment of innovation-oriented entities determined the need to move from the probabilistic models used to describe processes in the economy to the use of fuzzy set theory. As a result one need to develop and implement a qualitatively new model of innovative development - the model of "triple helix" (universities - government - industry ) or model of strategic innovation networks. Its key feature is acknowledgment as a leading network -level of participants interactions, as key institutions - institutions that initiate the creation and dissemination of new knowledge $[1,3,5]$.

Three-dimensional model of the " double helix " involves the interaction of the traditional universities coordinate system, public authorities and entrepreneurs are now replaced by a model where the content of pair interactions is influenced by a third party, which is at the same time in conjunction with the other members of the model. As universities which are capable to act as subjects of the Russian Federation in the model are the federal universities, integrated research and educational potential of the region (Federal District), as well as research universities, concentrated the potential of industrial science and education activities. This causes a high level of uncertainty of the result, dynamics and variability of innovation systems. Interaction in the framework of the " triple helix "model implies substitution ( addition , redistribution ) of participants functions, the ability to realize the key competencies to ensure efficient allocation and reallocation of resources.

\section{Theory}

The Triple Helix theory was devised in Great Britain and Holland in the early XXI century by professor of Newcastle University Henry Etzkowitz and professor of the University of Amsterdam Loet Leydesdorff.

In ancient Mesopotamia, a triple helix water screw, invented to raise water from one level to another, was the basis of a hydraulic system of agricultural innovation that irrigated ordinary farms as well as the Hangong Gardens of Babylon, one of the seven wonders of the ancient world $[8,11]$.

The Triple Helix symbolizes a union between government, business and university, which are the key elements of innovative system in any country. (Fig.1) 


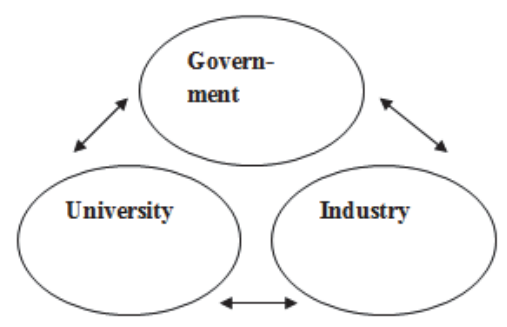

Figure 1. The structure of Triple Helix

The Triple Helix model presents interaction of certain institutions at every stage of innovative product development. Government and university interact at the initial stage, i.e. conception of an idea. Thereafter university cooperates with business in technology transfer. Eventually, a final product is commercialized in the market by joint effort of government and business. [2, 5]

The role of university in the Triple Helix model is indisputable. Majority of countries nowadays are in transition to economy of knowledge, where competitiveness of a country is primarily defined by know-how and sophisticated technologies. Therefore, universities carrying out research and development become a paramount asset in scienceintensive production.

\section{Results}

The implementation of "triple helix" model leads to a change in the innovation cycle configuration. During the knowledge generation phase (creative phase) there is the interaction between the government and the university, which results the formation of the competitive potential of the latter and its implementation in the form of competitive advantage. During the phase of innovation transfer dominates the interaction of university and industry, thereby reducing the transaction costs of information search costs and protection of property rights, especially intellectual. This creates a synergistic effect and is implemented in the form of positive externalities of innovation.

At the same time this interaction achieves Pareto - optimal volume of public goods and overcomes the limitations of the budget funding of higher education. Positive externality of innovation and increasing competitive capacity of businesses provides isolation of the innovation cycle on the final phase of which public-private partnerships is implemented as a tool for innovation commercialization. Thus transformation and diversification phase of economic innovation into the economic tradition as the final phase of the economic cycle, which involves the conversion of the innovations into the fundamental basis of the economic system, does not imply the decline of innovation $[6,9,10]$.

The implementation of this model let's to consider as one of the axes of the space the economic time as the correlation between the frequency of transactions. The implementation of the innovation cycle leads to compaction of the economic time. In this condition the effectiveness of the implementation of this model is the recognition of the social innovation priority in the form of social communication, ensuring the formation of communicative competence of economic agents, ie University serves as the subject of investment into the human capital, represented not only with knowledge and skills but also with professional competences, creates the preconditions for the formation of social communications, their potential is realized at the level of innovative entities (Microsoft Corporation, IKEA International Group and others, created with the participation of students ( graduates) of one university ).

A government-pulled the triple-helix model of innovation has the following characteristics:

- Government initiates and controls significant projects for social innovations;

- Most research universities and large-scale enterprises are affiliated to government;

- The top leaders' ideas and thoughts give direction and government policy and resolution are the batons to carry out the leaders will;

- Government organizes primary innovation agents, such as high-tech development zones (including incubators, science parks), technology and intellectual property markets.

Also such government that undertakes measures on triple helix model implementation has some advantages and disadvantages [7].

The advantages:

- Much more easier to achieve large-scale innovation projects; 
- Protecting university interest in entrepreneurship through policies;

- Consensus forming in regional innovation;

- Artificially fostering university-industry links by government authority;

The disadvantages:

- University-industry joint innovations tending to be "shows", rather than real ventures - after all personnel, equipment and funds in the two parties are both from the state;

- University and industry possibly losing the flexibility to deal with problems in the innovation process;

- $\quad$ The government's needing to "pull" university and industry forward [5].

\section{Conclusions}

The triple helix model attempts to capture the transformation of roles and relationships among the emerging primary institutional triad of university-industry-government. University, industry and government are conceptualized as intertwined spirals with different relations to each other in the classic innovation regimes. $[4,10]$

As the university takes up a new role in innovation promoting, it becomes transformed. As firms take their new role in continually adapting and raising their technological level, they become a bit closer to what a university does. As government plays a role as public entrepreneur it becomes a bit more like the industrial and academic spheres in realizing the importance of knowledge in creating the new economy and new society

The implementation of the model of "triple helix " in a localized spatial formation results in the formation of a favorable climate for innovation, as it promotes the development of its components, namely the accumulation of innovative capacity in turnover due to the involvement of all participants resource model, the combination of which provides a synergistic effect due to the increase of innovative activity which is realized because of transaction costs and innovation risks reducing.

\section{References}

Glebova I.S., Rodnyansky D., Sadyrtdinov R., Khabibrakhmanova R. and Yasnitskaya Y. Evaluation of Corporate Social Responsibility of Russian Companies Based on Nonfinancial Reportingll Middle-East Journal of Scientific Research 13 (Socio-Economic Sciences and Humanities): 143-148, 2013.

Safiullin L.N., Ismagilova G.N., Safiullin N.Z., Bagautdinova N.G. The development of welfare theory in conditions of changes in the quality of goods and services (2012) World Applied Sciences Journal 18 (Special Issue of Economics), pp. 144-149.

Carlsson, B. Internationalization of Innovation Systems: A Survey of the Literature. Research Policy,(2006)35(1),56-67.

Bagautdinova, N.G., Tsvetkova, G.S., Novenkova, A.Z. The interaction of formal and informal market institutes // World Applied Sciences Journal, 27(13), 2013, 58-61.

Markov, V.A., Bagautdinova, N.G., Yashin, N.S. Improvement of instruments of the state cluster-based policy in the contexts of economic entities interrelation asymmetry // World Applied Sciences Journal, 27(13), 2013, 130-134.

Sarkin, A.V., Bagautdinova, N.G., Averianov, B.A. Development and implementation of adaptive science-intensive manufacture management system based on management processes automation // World Applied Sciences Journal, 27(13), 2013, 159-164.

Etzkowitz, H.(2006). "The new visible hand: An assisted linear model of science and innovation policy", Science and Public Policy,Vol.33,No.5,June,pp,310-320(11)

Leydesdorff, L. (2006).The Knowledge-Based Economy: Modeled, Measured, Simulated. Boca Raton, FL: Universal Publishers.

Leydesdorff , L. \& Etzkowitz, H.(1998).The Triple Helix as a model for innovation studies. Science and Public Policy, 25(3), $195-203$.

Gainova R.A., Shaidullin R.N., Safiullin L.N. and Maratkanova E.M. Infrastructural Component in Maintenance of Competitiveness of Region// World Applied Sciences Journal, 27(13), 2013, pp. 97-101.

Safiullin M.R., Samigullin I.G. and Safiullin L.N. Model of Management of Competitiveness of a Machine-building Complex// World Applied Sciences Journal, 27(13), 2013, pp. 212-216. 
